\title{
Patterns of respiratory behavior
}

\author{
D. DWAYNE SIMPSON* \\ Institute of Behavioral Research, Texas Christian University, Fort Worth, Texas 76129
}

\begin{abstract}
The existence and generalizability of characteristic individual patterns of breathing were investigated. Pneumographic respiration recordings were obtained for eight male Ss while they performed a variety of experimental tasks during six different recording sessions. Categorical sorts of sets of respiration record segments were performed by three judges, and they were highly successful in detecting distinctive respiratory characteristics for sorting segments from different Ss into categories representing individual Ss. Implications for further research are discussed.
\end{abstract}

Despite widespread recognition of the apparent tendency of individuals to exhibit consistent styles, or patterns, of respiratory behavior, surprisingly little research can be found on the existence of such patterning or its behavioral significance. In view of the influence of respiration on other physiological systems, a long-established laboratory practice involves careful monitoring of respiration when studying other physiological measures; however, relatively little research has focused on respiration in its own right. Several investigators have noted the occurrence of "large between-subject variability in respiratory behavior" (Lacey \& Lacey, 1965; Brenner \& Hothersall, 1967). Others have commented more pointedly on their observations of "characteristic differences between respiratory patterns of different individuals" and "constancy of breathing patterns" (Alexander \& Saul, 1940; Heim, Knapp. Vachon, Globus, \& Nemetz, 1968). Collectively, these reports present considerable agreement on the existence of individualized breathing styles.

The most intriguing implications of constancy of respiratory patterning are related to the prediction and possibly the control of other behaviors. Nielsen and Roth (1929), for example, have reported that individuals whose breathing styles were characterized by "frequent and extremely deep inspirations" showed a greater incidence of hypertension than expected by chance. Similarly, Friedman (1969) has pointed out that individuals exhibiting a personality-behavior pattern associated with proneness to coronary artery disease also tend to sigh frequently. Friedman remarked that "this sigh differs from the long, implosive, inspiratory sigh of the patient with an anxiety neurosis in that it takes place

\footnotetext{
*Appreciation is expressed to Dr. S. B. Sells for suggestions concerning this manuscript and to Dr. Robert G. Demaree for his advice and assistance throughout the research. This paper was based upon a dissertation submitted to Texas Christian University in partial fulfillment of the requirements for the $\mathrm{PhD}$ degree; the research was supported in part by the Rehabilitation Services Administration under RSA Research Training Grant RH-2.
}

at or toward the end of the expiratory phase of respiration [p. 89]."

The significance of respiratory maneuvers for their indirect influence on cardiovascular and bioelectrical events of the body is well known. Katkin and Murray (1968), who reviewed instrumental conditioning studies of autonomic functions, cited many studies in which the lack of proper controls for possible mediating effects of respiration and skeletal activities prevented conclusive interpretation of results. Brenner and Hothersall (1967) found that control of heart rate appeared to be facilitated in a condition involving free respiration as compared to paced breathing. The use of respiration in heart rate control has been further established by Sroufe (1971). Breathing control and the focusing of attention on respiratory behavior have also been emphasized in several relaxation and meditation techniques, such as in Yoga exercises, Zen meditation, and autogenic relaxation training (Schultz \& Luthe, 1959).

In summary, suggestive evidence has been reported regarding individual breathing patterns and possible association of particular respiratory characteristics with other important behaviors, such as cardiovascular functions. The present study was undertaken in order to obtain empirical evidence concerning the presumed individuality of respiratory patterns and also to investigate the generalizability of such patterns across both occasions and tasks. In view of the lack of established parameters for the comprehensive characterization of respiratory behavior, the analysis of breathing patterns was based on categorical sorting procedures by experimental judges, using segments of respiration recordings. The relevant parameters noted by the judges in sorting the patterns were also examined as a means of guiding further development of quantitative descriptors for breathing patterns in the study of behavioral correlates.

\section{METHOD}

\section{Subjects}

The Ss for the study were eight male college student volunteers. Ages ranged from 18 to 22 years. None of the Ss 
were regular smokers, and none reported knowledge of having respiratory or cardiovascular disorders. Ss were paid $\$ 1.50$ for each of six 1-h experimental sessions and were promised bonuses upon completion of all sessions. The amount of the bonus ranged between $\$ 5.00$ and $\$ 15.00$ and was determined by the relative performance scores on tasks completed during the study.

\section{Apparatus}

Respiration was recorded with an E\& $M$ bellows pneumograph attached around the chest at the level of the xiphoid process. The recording was obtained on a single-channel Sanborn 151 recorder, at a paper speed of $5 \mathrm{~mm} / \mathrm{sec}$. Additional measures were recorded on an E \& M Physiograph-Six, but these are not discussed in the present report. The measures included respiration (nasal thermistor). heart rate. skin resistance, and finger pulse volume. Volumetric measures of respiration were also obtained with a 7-1 Collins Spirometer at the conclusion of each session.

Recordings were made while the $\mathrm{S}$ was seated comfortably in a modified dental chair located in a sound-attenuated and electrically shielded chamber. Recording and other equipment were located in an adjoining room with visual access. via a one-way mirror, of the $\mathrm{S}$. The $\mathrm{S}$ faced the wall opposite the one-way mirror and wore headphones throughout all sessions.

\section{Procedures for Recording Respiration Data}

Physiological recordings were obtained continuously during a practice session and during each of the six experimental sessions. Ss were informed that the study was designed to investigate the relationship between physiological functioning and performance on several different tasks. In the practice session, recording sensors were explained as they were attached to the $S$. The various tasks to be used in experimental sessions were then explained and practiced by the $S$.

A variety of tasks was employed in the study. They included simple and discrimination reaction-time tasks (fixed 5-sec foreperiods), a time-estimation task of a 5-sec interval, pursuit and compensatory tracking tasks using an oscilloscopic feedback display, and word-recognition tasks (one requiring solutions to anagrams and one involving the recognition of words which were obliterated through partial deletions of letters). A total of 12 different tasks was included; some were performed more than once in the experimental sessions.

All experimental sessions lasted approximately $1 \mathrm{~h}$. Sessions for each $\mathrm{S}$ were scheduled at the same time of day throughout the study, and the interval of time between successive sessions for individual Ss ranged between 2 and 7 days. Ss were screened for respiratory ailments and drug medication during the study. Further, it was requested that they not sleep, perform vigorous exercise, or eat during $1 \mathrm{~h}$ prior to any session, and not smoke or drink (except water) during 30 min prior to any session.

When a $S$ arrived for a session, recording sensors were attached and about $10 \mathrm{~min}$ were then allowed before testing began. Three tasks were performed by the $S$ during each session, and the order of task presentations was different for each S. Instructions were given immediately prior to each task. The tasks lasted approximately $7 \mathrm{~min}$ each, and those within sessions were separated by rest periods of $3 \mathrm{~min}$.

\section{Procedure for Sorting Respiration Records}

Categorical sorts of respiration records were performed by three judges. Respiration records taken during each task were divided into $1035-\mathrm{sec}$ segments. The segments were taken at preselected intervals throughout the tasks in a manner such that the occurrence of task stimuli was comparable in all segments. Segments containing movement artifacts were eliminated from consideration. Seven of the remaining segments from each task were randomly selected and were used in the sorts by the judges.
This procedure was repeated for each task and each S. Thus, seven segments of respiration records were produced for each $S$ during every task.

These respiration record segments were the materials sorted into categories by the judges. Experimental control was exerted over characteristics of the respiration tracings during the recording of the segments in order to eliminate extraneous cues as a possible basis for sorting. For instance. the amplitude of the recordings was standardized so that the height of the respiration waveform was approximately the same for all Ss on all tasks. This was done partially because of the lack of a satisfactory method for calibrating pneumographic tracings with respect to tidal volume. More importantly, however, the objective of the present study was to consider the pattern of respiratory cycles, independently of individual differences in tidal volume.

Three female undergraduate students were paid to serve as judges. The procedure for the selection of judges was based on the observation by Evans ${ }^{1}$ that individual differences exist in the pattern-recognition abilities of humans and that these abilities are relatively consistent over time. In order to obtain individuals who appeared to be proficient in the detection of pattern similarities, three persons were selected as judges who made the highest performance scores in a schematic concept formation experiment by Hastings (1970). In the Hastings study, individuals performed a pattern-recognition task in which paired comparisons were made of graphic patterns represented as polygons. The three individuals who were selected as judges were considered to have demonstrated superior pattern-recognition capabilities.

Working independently, the judges were given sets of record segments and asked to sort them into categories. The judges knew that the segments represented respiratory behavior but were not told the number of Ss involved in the study nor the specific nature of the tasks performed by Ss. In each sort, judges were merely instructed to assign "similar" segments to the same categories, but to determine for titemselves the number of categories required and the number of segments assigned to each category.

\section{Between-S Sorts}

Sorts were completed first for each experimental task, using the segments from all Ss on that task. Each sort was based on a set of 56 segments, representing 7 segments from each of eight Ss. Sixteen between-S (within-task) sorts were conducted, 1 for each of the 16 task presentations (excluding 2 presentations in which tasks were repeated).

\section{Within-S Sorts}

The judges also performed within-S sorts, conducted separately for each of the eight Ss. A within-S (between-task) sort was based on a sample of 64 segments, all from the same $S$, but using a random sample of 4 segments taken from each of the 16 experimental tasks used in the between-S sorts.

After the completion of each between-S and within-S sort, the judges provided a written and graphic description of the segment categories constructed. They were asked to indicate the distinguishing characteristics of each category of segments and to note similarities and contrasts between categories. The judges performed the sorts in a series of sessions, over a period of approximately 2 weeks.

\section{RESULTS}

The between-S data were examined to determine whether the judges could distinguish the respiration records of different individuals, and this was done by counting the number of segments for different Ss in each 
of the categories. Each category was attributed to the $\mathrm{S}$ with the largest number of segments in it, and all segments from other Ss included were regarded as misclassifications, or errors. The errors in all categories were then summed and the total recorded as the error count for that sorting task. If each category in a sort contained only segments from a single $S$, the error count was zero. In instances in which judges used more than 8 categories, the same error rule was applied, and in some sorts, therefore, a $\mathrm{S}$ was represented by more than 1 category. It is noteworthy that no judge used more than 12 categories and that each judge used only 8 categories in at least $50 \%$ of her sorts (one judge always used 8 categories).

In a few cases, categories were formed in which no one $S$ had the largest number of segments, i.e., the segments included represented two or more Ss with equal numbers of segments. In such instances, one $\mathrm{S}$ was chosen arbitrarily to represent the category and all segments from the remaining Ss were counted as errors.

Sample respiration segments used in the sorts by judges for a reaction-time task to tones [RT(3)] and a compensatory tracking task [T(2)] are shown in Figs. 1 and 2, respectively. One record for each of the eight Ss (designated as a through $\mathrm{h}$ ) is included in each figure, and inhalations are represented by upward deflections in

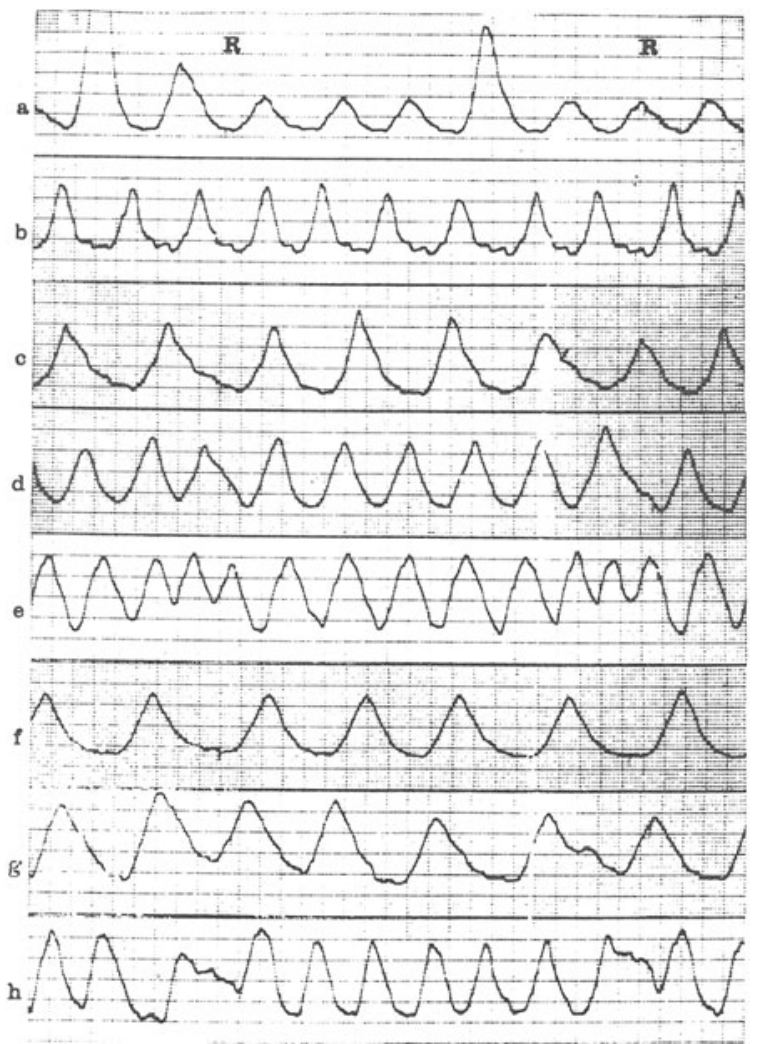

Fig. 1. Sample respiration segments from Ss during a reaction-time task $[R T(3)]$. (Upward deflection = inhalation: $R$ = approximate points of $\mathrm{RT}$ responses).

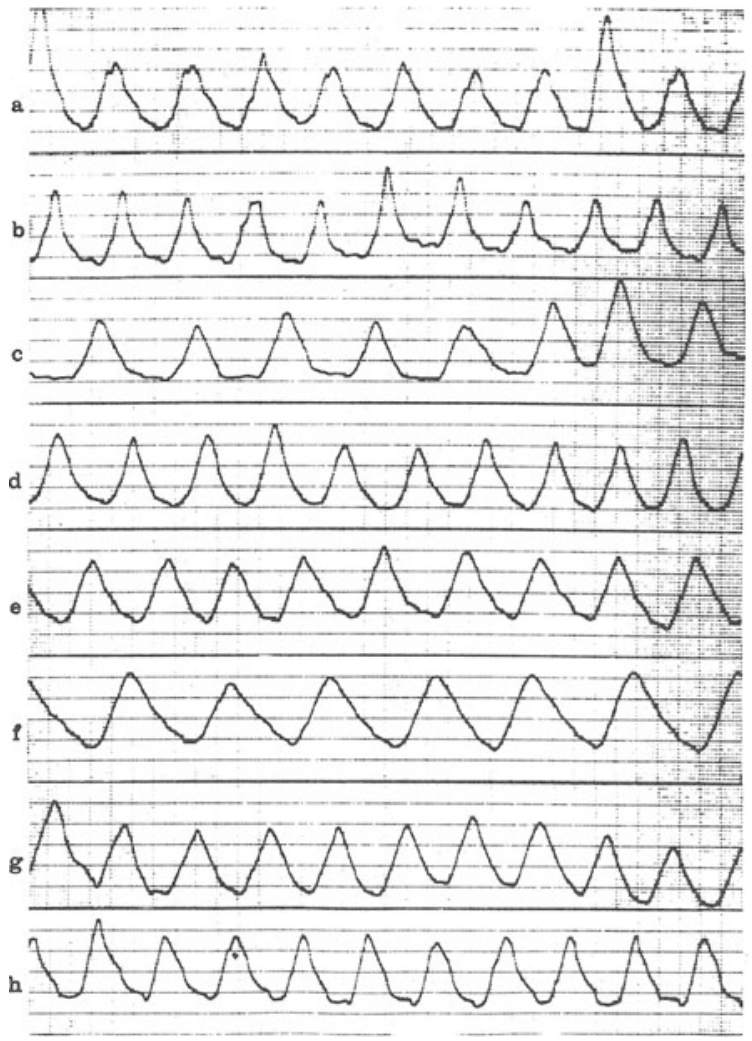

Fig. 2. Sample respiration segments from Ss during a tracking task $[\mathrm{T}(2)]$.

the tracings. The between-S results indicated strongly that the judges were able to distinguish reliably between respiration segments from different Ss. Table 1 summarizes the outcomes for each judge and for each of the 16 sorts. It shows the number of categories used by the judges in each sort and the number of errors committed. It can be seen that, on the average, across all 16 sorts, Judge A misclassified only 1.8 segments (3\%) out of the total of 56 sorted for each task, while Judge B made an average of 6.1 errors $(11 \%)$ and Judge $C$ made an average of 6.3 errors $(11 \%)$.

When the sets of respiration segments associated with particular tasks were considered, it was found that the judges committed more sorting errors for some tasks than for others. This was particularly true for the tracking tasks where the respiration patterns generally were more regular in rate and amplitude characteristics (see Fig. 2). Although the tracking task sorts appeared to be more difficult for the judges, the patterns were still distinguishable.

A description of the categories formed by judges in two of the sorts is provided in Table 2. This table presents a detailed account of a sample of the results summarized in Table 1. Sorts by each judge for Tasks $\mathrm{RT}(3)$ and $\mathrm{T}(2)$ are shown, indicating the number of categories formed and the assignments to each. Categories are numbered arbitrarily, and the number of 
Table 1

Summary of Sortings Outcomes by Judges Showing the Number of Categories Formed and the Number of Misclassifications in Each Sort

\begin{tabular}{|c|c|c|c|c|c|c|}
\hline \multirow[b]{2}{*}{ Tasks } & \multicolumn{2}{|c|}{ Judge A } & \multicolumn{2}{|c|}{ Judge B } & \multicolumn{2}{|c|}{ Judge C } \\
\hline & $\begin{array}{l}\text { Number of } \\
\text { Categories }\end{array}$ & $\begin{array}{c}\text { Number of } \\
\text { Errors }\end{array}$ & $\begin{array}{l}\text { Number of } \\
\text { Categories }\end{array}$ & $\begin{array}{c}\text { Number of } \\
\text { Errors }\end{array}$ & $\begin{array}{l}\text { Number of } \\
\text { Categories }\end{array}$ & $\begin{array}{c}\text { Number of } \\
\text { Errors }\end{array}$ \\
\hline RT (1) & 8 & 0 & 8 & 4 & 8 & 7 \\
\hline RT (2) & 8 & 1 & 12 & 3 & 9 & 6 \\
\hline RT (3) & 8 & 0 & 10 & 1 & 8 & 8 \\
\hline RT (4) & 8 & 2 & 9 & 6 & 8 & 5 \\
\hline RT (5) & 8 & 3 & 8 & 10 & 10 & 7 \\
\hline RT (6) & 8 & 1 & 8 & 4 & 8 & 0 \\
\hline RT (7) & 8 & 2 & 8 & 9 & 8 & 4 \\
\hline RT (8) & 8 & 2 & 8 & 3 & 8 & 6 \\
\hline TE (1) & 8 & 2 & 12 & 0 & 9 & 3 \\
\hline TE (2) & 8 & 1 & 8 & 3 & 9 & 3 \\
\hline$T(1)$ & 8 & 5 & 8 & 7 & 9 & 5 \\
\hline$T(2)$ & 8 & 3 & 8 & 15 & 9 & 10 \\
\hline$T(3)$ & 8 & 3 & 8 & 15 & 8 & 7 \\
\hline WR (1) & 8 & 0 & 8 & 7 & 10 & 12 \\
\hline WR (2) & 8 & 0 & 9 & 3 & 9 & 6 \\
\hline WR (3) & 8 & 3 & 10 & 8 & 8 & 12 \\
\hline Average & 8.0 & 1.8 & 8.9 & 6.1 & 8.6 & 6.3 \\
\hline
\end{tabular}

$R T=$ reaction time

segments assigned to each category by each judge is indicated with the identification of the $S$ segments included. The sorting outcomes represent the ranges of apparent difficulty levels for the judges, including one task with generally few sorting errors and one with many errors. In general. the fewest sorting errors were associated with the reaction-time and time-estimation tasks and the largest number of errors with the tracking tasks.
The within-S results indicated that the judges experienced considerable difficulty in distinguishing between segments recorded from the same $S$ during different occasions and experimental tasks. As contrasted to the between-S sorts, the judges expressed little confidence in their abilities to isolate distinctive categories of within-S segments. Nevertheless, the sorting of segments suggested that the categories used separated the types of tasks. It can be observed in Figs. 1 and 2,

Table 2

Number, Size, and Content of Categories Resulting from Between-S (Within-Task) Sorts*

\begin{tabular}{|c|c|c|c|c|c|c|c|c|c|}
\hline & \multicolumn{3}{|c|}{ Judge A } & \multicolumn{3}{|c|}{ Judge B } & \multicolumn{3}{|c|}{ Judge C } \\
\hline & $\begin{array}{l}\text { Category } \\
\text { Number }\end{array}$ & $\begin{array}{c}\text { Category } \\
\text { Size }\end{array}$ & $\begin{array}{r}\text { Category } \\
\text { Content }\end{array}$ & $\begin{array}{c}\text { Category } \\
\text { Number }\end{array}$ & $\begin{array}{c}\text { Category } \\
\text { Size }\end{array}$ & $\begin{array}{r}\text { Category } \\
\text { Content }\end{array}$ & $\begin{array}{l}\text { Category } \\
\text { Number }\end{array}$ & $\begin{array}{c}\text { Category } \\
\text { Size }\end{array}$ & $\begin{array}{r}\text { Category } \\
\text { Content }\end{array}$ \\
\hline $\begin{array}{l}\text { Task } \\
\text { RT (3) }\end{array}$ & $\begin{array}{l}1 \\
2 \\
3 \\
4 \\
5 \\
6 \\
7 \\
8\end{array}$ & $\begin{array}{l}7 \\
7 \\
7 \\
7 \\
7 \\
7 \\
7 \\
7\end{array}$ & $\begin{array}{l}7 \mathrm{a} \\
7 \mathrm{~b} \\
7 \mathrm{c} \\
7 \mathrm{~d} \\
7 \mathrm{e} \\
7 \mathrm{f} \\
7 \mathrm{~g} \\
7 \mathrm{~h}\end{array}$ & $\begin{array}{r}1 \\
2 \\
3 \\
4 \\
5 \\
6 \\
7 \\
8 \\
9 \\
10\end{array}$ & $\begin{array}{l}7 \\
7 \\
5 \\
8 \\
6 \\
7 \\
5 \\
7 \\
2 \\
2\end{array}$ & $\begin{array}{l}7 \mathrm{a} \\
7 \mathrm{~b} \\
5 \mathrm{c} \\
7 \mathrm{~d}, \mathrm{le} \\
6 \mathrm{e} \\
7 \mathrm{f} \\
5 \mathrm{~g} \\
7 \mathrm{~h} \\
2 \mathrm{c} \\
2 \mathrm{~g}\end{array}$ & $\begin{array}{l}1 \\
2 \\
3 \\
4 \\
5 \\
6 \\
7 \\
8\end{array}$ & $\begin{array}{l}7 \\
7 \\
7 \\
7 \\
7 \\
7 \\
7 \\
7\end{array}$ & $\begin{array}{l}7 \mathrm{a} \\
7 \mathrm{~b} \\
4 \mathrm{c}, 3 \mathrm{~g} \\
6 \mathrm{~d}, \mathrm{le} \\
6 \mathrm{e}, 1 \mathrm{~d} \\
7 \mathrm{f} \\
4 \mathrm{~g}, 3 \mathrm{c} \\
7 \mathrm{~h}\end{array}$ \\
\hline $\begin{array}{l}\text { Task } \\
\text { T (2) }\end{array}$ & $\begin{array}{l}1 \\
2 \\
3 \\
4 \\
5 \\
6 \\
7 \\
8\end{array}$ & $\begin{array}{l}8 \\
7 \\
6 \\
7 \\
8 \\
7 \\
6 \\
7\end{array}$ & $\begin{array}{l}7 \mathrm{a}, \mathrm{ld} \\
7 \mathrm{~b} \\
6 \mathrm{c} \\
6 \mathrm{~d}, \mathrm{lg} \\
7 \mathrm{e}, \mathrm{lc} \\
7 \mathrm{f} \\
6 \mathrm{~g} \\
7 \mathrm{~h}\end{array}$ & $\begin{array}{l}1 \\
2 \\
3 \\
4 \\
5 \\
6 \\
7 \\
8\end{array}$ & $\begin{array}{l}6 \\
7 \\
5 \\
9 \\
8 \\
8 \\
7 \\
6\end{array}$ & $\begin{array}{l}4 \mathrm{a}, 2 \mathrm{e} \\
6 \mathrm{~b}, \mathrm{le} \\
5 \mathrm{c} \\
5 \mathrm{~d}, 4 \mathrm{~g} \\
4 \mathrm{e}, 1 \mathrm{~d}, 3 \mathrm{~g} \\
7 \mathrm{f}, \mathrm{lc} \\
7 \mathrm{~h} \\
3 \mathrm{a}, \mathrm{lb}, 1 \mathrm{~d}, \mathrm{lc}\end{array}$ & $\begin{array}{l}1 \\
2 \\
3 \\
4 \\
5 \\
6 \\
7 \\
8 \\
9\end{array}$ & $\begin{array}{r}7 \\
7 \\
4 \\
2 \\
5 \\
7 \\
11 \\
7 \\
6\end{array}$ & $\begin{array}{l}7 \mathrm{a} \\
7 \mathrm{~b} \\
4 \mathrm{c} \\
\mathrm{ld}, \mathrm{lc} \\
4 \mathrm{e}, \mathrm{lc} \\
7 \mathrm{f} \\
6 \mathrm{~g}, 5 \mathrm{~d} \\
7 \mathrm{~h} \\
3 \mathrm{e}, \mathrm{lc}, \mathrm{ld}, \mathrm{lg}\end{array}$ \\
\hline
\end{tabular}

*In the category content column. letters denote subjects; the numeral immediately preceding each letter indicates the number of segments for that subject. 
for instance, that task-specific idiosyncrasies were present, particularly for some Ss. During the RT tasks in general. Ss often revealed characteristic breathing maneuvers during the $5-\mathrm{sec}$ interval between the warning signal and the RT response. That is, some Ss appeared to alter their breathing during this period, and this generally resulted in their being in the same phase of respiration at the time of response for each RT trial. Another tendency, for one S, was to hyperventilate during this interval (see e in Fig. 1). On the other hand, respiration generally appeared more regulated during the tracking tasks, as illustrated in Fig. 2. The degree of breathing variation across tasks, however, varied for the Ss in that the task distinctions revealed by the sorts were less consistent for some Ss (a, b, and c) than for others.

Examination of the judges' descriptions for the categories constructed in the between-S sorts revealed that they used a variety of cues in discriminating between the respiration records of different Ss. Duration of the breathing cycle, or rate, was of course an important feature of the patterns, but other characteristics were also significant in that records from Ss with similar breathing rates were distinguishable. The most common features noted, besides rate, involved pause times following exhalation, sighing or periodic deep breaths, sharpness of inhalation and exhalation, and general regularity or rhythm of the pattern. Typical descriptions are illustrated in Fig. 1, which shows variations in breathing depth (a and e), sharp inhalation and exhalation with relatively long pause times after exhalation (b), irregular rhythm and waveform (e and h), and highly regulated waveform with a gradual exhalation-to-inhalation transition (f). It should be noted, however, that some of the cues are apparently specific to the RT task and disappear or change in the tracking task displayed in Fig. 2. In particular, the irregular waveform of $\mathrm{Ss} e$ and $h$ preceding the RT response in Fig. 1 disappeared in Fig. 2.

In general, the judges gave similar descriptions of the segment categories for each $\mathrm{S}$, and they were also consistent in their descriptions of segment categories of a $\mathrm{S}$ across occasions and tasks (particularly similar tasks). In anticipation of future research, a set of measures was constructed, incorporating the features noted by the judges, as a means of approaching quantitative descriptions of the distinguishing pattern parameters. These measures were devised with reference to the standard 35 -sec segments of respiration records used in the present study, but are applicable to other time durations. Several of the measures can be easily determined for each record segment; these are the average duration or length of the breathing cycles, and the variance across cycles; the average duration of the midinhalation phase to the midexhalation phase of the cycles (a measure of the rapidity of breathing), and the variance across cycles: and the variance of inhalation amplitude (trough to peak) for the breathing cycles (average amplitude of the respiration cycles are not included since this was experimentally controlled in the present study). The remaining measures are more difficult to determine but seem to reflect important pattern information; they involve the sharpness or shape of the exhalation phases, and the variation across breathing cycles, and the length of pause time or respiratory inactivity after exhalation, and the variation across breathing cycles. Depending on the manner in which these measures are determined, there may be some overlap of information, but as a whole they encompass the features detected by the judges and reportedly used in performing the sorts.

\section{DISCUSSION}

Evidence has been presented supporting the existence of individualized patterns of breathing which is consistent with the notions regarding breathing styles expressed by Alexander and Saul (1940) and by Heim et al (1968). Characteristics of individual respiratory patterns were found in general to retain consistency within specific tasks, as well as within types of tasks, but they also varied, in some cases, as a function of task differences. The pattern variations observed between types of tasks appeared to be more marked for some individuals than for others.

Further analysis of these data, based on scores derived with the measures defined above from judges' descriptions of discriminating characteristics of the records examined, has shown that statistical classification procedures can be used and that these correspond highly with the sorting outcomes by judges (Cornelius, Simpson, \& Demaree, 1971). The classification of segments into categories, on the basis of linear combinations (determined by multiple discriminant analysis) of the respiration pattern measures entered into a standard Bayesian classification procedure, resulted in misclassification of less than $10 \%$ of the segments in a between-S sorting task. The most important and discriminating measures were found to be mean respiration cycle time, mean width of the inhalation-exhalation phases, mean pause-time durations, mean ratings of the sharpness of exhalation phases (measures of pause time and sharpness of exhalation were based on ratings), and variance of inhalation amplitude. While this analysis was preliminary, in that data from only a single task [RT(3)] were utilized and some refinements are needed in the measurement procedures for some of the measures, the results demonstrated that the distinctive characteristics of breathing patterns may be captured through the analysis of quantitative measurements.

The apparent tendency which was noted for some individuals to alter breathing just prior to a response in the RT tasks has also been examined in more detail (Nelson \& Simpson, 1971). Several physiological recordings were obtained from 14 Ss using a simple RT task with a $5-\sec$ fixed foreperiod and a light as a 
respond signal. The results indicated that after a few trials. Ss began to control breathing such that they tended to be consistently in the same phase of the breathing cycle at the time of response for each RT trial. Most of the Ss tended to be late in the exhalation phase at the time they made an RT response, but there were individual differences in the extent to which this occurred. However. no consistent relationships of breathing phases at the RT response were found with either RT performance or heart rate.

The respiration recordings used in the present research were obtained with a bellows pneumograph. and thus the tracings more precisely reflected patterns of chest movement than of air-volume exchange per se. The two measures are highly related, but the relationship might have been improved if a balanced pair of pneumographs had been used around the chest and stomach (Ax, 1964). The use of a nasal thermistor provided a secondary measure of breathing activity; since this is based upon actual air exchange, it served to aid in detecting and eliminating artifactual pneumographic recordings. A procedure similar to one employed by Heim et al (1968) was used to calibrate pneumographic pen deflections with respect to air-volume exchange (via a closed-system spirometer). The procedure was only partially successful, however. and several problems were encountered which detracted from its effectiveness. (For a more detailed discussion, see Simpson, 1971).

\section{SUMMARY AND CONCLUSIONS}

The distinctiveness and consistency of individual breathing patterns has been demonstrated in a small ,sample $(\mathrm{N}=8)$. but the diversity of respiratory patterns in the population and the nature of their relationships to other behaviors require further investigation. Measures of respiratory behavior have been suggested which are more comprehensive than those commonly used in physiological research, although the usefulness of these or other measures depends on the extent to which they represent breathing parameters, which are in turn related to other behaviors. The distinctiveness of individual patterns per se is of limited interest, but the fact that they remain constant over time is significant and suggests that the examination of specific respiratory parameters may lead to the detection of important medical and other behavioral correlates. With that, the prediction and possibly the control of certain behaviors could be improved.

\section{REFERENCES}

Alexander, F., \& Saul, L. J. Respiration and personality-a preliminary report: Part I. Description of the curves. Psychosomatic Medicine, 1940, 2, 110-118.

Ax, A. F. Goals and methods of psychophysiology. Psychophysiology, 1964, 1, 8-25.

Brenner, J., \& Hothersall, D. Paced respiration and heart rate control. Psychophysiology, 1967, 4, 1-6.

Cornelius, E. T., Simpson, D. D., \& Demaree, R. G. Quantification of respiratory patterns: A preliminary report. Paper presented at the meeting of the Southwestern Psychological Association, San Antonio, Texas. May 1971.

Friedman, M. Pathogenesis of coronary artery disease. New York: McGraw-Hill, 1969.

Hastings, M. A. Feature selection: The effect of attribute variability on visual pattern recognition. Unpublished masters thesis, Texas Christian University, 1970.

Heim. E., Knapp, P. H., Vachon, L., Globus, G. G., \& Nemetz, S. J. Emotion, breathing and speech. Journal of Psychosomatic Research, 1968, 12, 261-274.

Katkin, E. S., \& Murray, E. N. Instrumental conditioning of autonomically mediated behavior: Theoretical and methodological issues. Psychological Bulletin, 1968, 70, $52-68$.

Lacey, B. C., \& Lacey, J. I. Cardiovascular and respiratory correlates of reaction time. Appended Preprint No. 3, June 1965, Fels Research Institute, Contract MH00623, National Institutes of Health.

Nelson, A. E., \& Simpson, D. D. Alteration of respiration during a reaction-time task. Paper presented at the meeting of the Southwestern Psychological Association. San Antonio, Texas, May 1971.

Nielsen, J. M., \& Roth, P. Clinical spirography. Archives of Internal Medicine, 1929, 43, 132-138.

Schultz, J. H., \& Luthe, W. Autogenic training: $A$ psychophysiological approach in psychotherapy. New York: Greene \& Stratton, 1959.

Simpson, D. D. An investigation of patterns of respiratory behavior. Unpublished doctoral dissertation, Texas Christian University, 1971.

Sroufe, L. A. Effects of depth and rate of breathing on heart rate and heart rate variability. Psychophysiology. 1971, 8, 648-655.

\section{NOTE}

1. Evans, S. H. Personal communication, 1970.

(Received for publication September 5, 1972; revision received November 28,1972 .) 